\title{
Retrograde Endoscopic Treatment of Completely Obstructed Anastomotic Stricture After Anterior Resection
}

\section{Abstract}

Ms $M$ is a 38 year female who has a history of severe endometriosis. She underwent resection of pelvic endometriosis, parital cystectomy and an anterior resection and loop ileostomy due to a rectosigmoid stricture. Post operative gastrograffin showed a patent anastomosis. The patient presented electively for closure of the ileostomy three months later. Under general anaesthesia, the patient was examined and it was found that the colorectal anastomosis was completely occluded. This article presents a novel procedure using a colonoscope with a cutting snare, Hegar's dilators and a Controlled Radial Expansion (CRE) balloon to reopen the lumen.

\section{Case report}

Ms $M$ is a 38 year old woman with a history of severe pelvic endometriosis. She underwent resection of the pelvic side wall endometriosis, partial cystectomy, anterior resection with a temporary loop ileostomy for a rectosigmoid stricture associated with full thickness colonic involvement. A routine post operative gastrograffin enema six weeks after the operation was performed to assess the anastomosis. This showed a patent lumen and no anastomotic leak.

The patient presented electively for reveral of the loop ileostomy three months later. She was examined under anaesthesia which revealed an extremely tight anastomosis with no obvious lumen extending from the rectum to the colon. Colonoscopy was performed, confirming these findings.

The colonoscope was then advanced through the distal limb of the ileostomy into the colon and down into the colorectal anastomosis. A large Hegar's dilator was introduced through the rectum and a cutting snare was used to cut onto the tip of the Hegar's dilator which immediately opened up the anastomosis. This was then dilated with
Jamish Gandhi1, Neil Avery ${ }^{2}$, J P Keating ${ }^{3}$

1 Surgical Registrar, Waikato Hospital, Waikato, New Zealand.

2 Ophthalmology Registrar, Dunedin Hospital, Dunedin, New Zealand.

2 Colon and Rectal Surgeon, Wellington Hospital, New Zealand.

Contact information:

Jamish Gandhi.

”j.gandhi@xtra.co.nz

Keywords

Anastomotic stricture, Colorectal anastomosis, Colonoscopy. 
a CRE balloon and further Hegar's dilators to 15 $\mathrm{mm}$ in diameter.

Ms $\mathrm{M}$ had an uncomplicated post-operative course. She had an outpatient flexible sigmoidoscopy arranged. This was performed three months later and revealed a normal anastomosis and no dilation was required.

\section{Discussion}

Anastomotic stricture is a recognised complication of an anterior resection. Strictures occur in between 2 and $7 \%$ of cases of colonic resection and are often the result of a cicatrical response [1]. As such gastrograffin enema is performed to ensure patency and exclude leak. This will often reveal obstruction before closure is attempted. There have been numerous methods for treatment of stricture post anterior resection. The preferred technique for management has been balloon dilation of the stricture. This uses a balloon to disrupt scar tissue and have been used with good short term success. Other endoscopic techniques used include stricture incision using monopolar electrosurgery snare or a needle knife, and intralesional corticosteroid [1, 2].

Endoscopic therapy is not however commonly used in cases of complete anastomotic obstruction, though this has been previously treated using a rendevous maneuver using both retrograde and antegrade endoscopy. Using this technique the obstruction is traversed with a guidewire, perforating needle or a biopsy forceps using transilluminatry guidance. Once the guidewire is passed it is captured by the corresponding endoscope allowing for subsequent wire guided dilation [1, 2]. Similar techniques have been used to dilate complex oesophageal strictures [3].

This case describes a novel procedure for opening the lumen of a completely obstructed anastomosis which was discovered intraoperatively. The main difference is instead of guidance via guidewire, the cutting snare of the colonoscope was used to create an opening directed towards a Hegar's dilator which had been inserted per-rectum. After the lumen was opened a standard dilation with a balloon was performed and the ileostomy closed. The procedure was successful and tolerated well by the patient. Recovery was uncomplicated and a subsequent flexible sigmoidoscopy revealed a normal anastomosis and no further dilation was required.

\section{References}

1. Kaushik N, Rubin J, McGrath K. Treatment of benign complete anastomotic obstruction by using an endoscopic renezvous technique. Gastrointestinal Endoscopy. 2006; 63(3): 727-730.

2. Dedogni G, Ricci E, Pedrazzoli C et al. Endoscopic dilation of anastamotic colonic stenosis by different techniques: an alternative to surgery? Gastrointestinal Endoscopy. 1987; 33(1): 21-24.

3. Bueno R, Jaklitsch M, Swanson S. A new technique for the dilation of completely obstructed esophageal strictures. Gastrointestinal Endoscopy. 2000; 51(4): 3561.

\section{Comment on this article:}

\section{(f) $[$ in $8+\mathbf{S} P$}

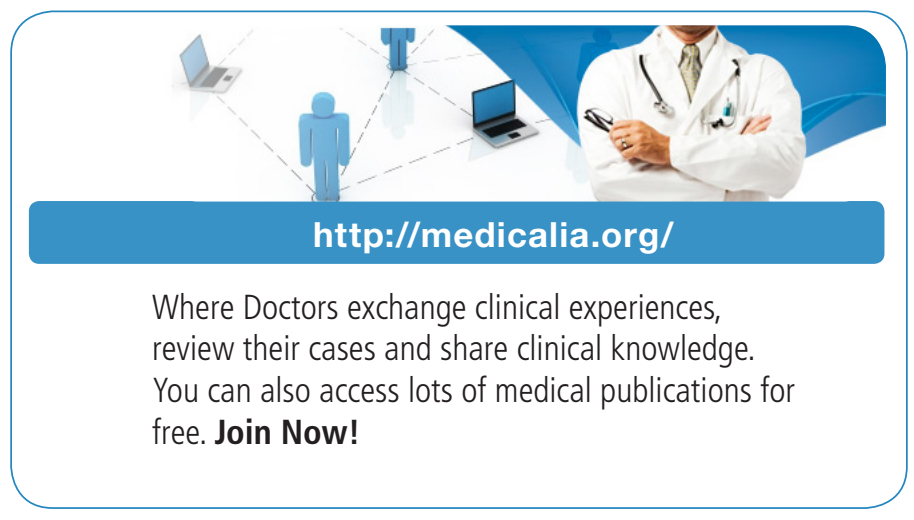

Publish with iMedPub

http://www.imed.pub

International Archives of Medicine is an open access journal publishing articles encompassing all aspects of medical science and clinical practice. IAM is considered a megajournal with independent sections on all areas of medicine. IAM is a really international journal with authors and board members from all around the world. The journal is widely indexed and classified Q1 in category Medicine. 